\title{
Mevalonate Kinase Deficiency
}

National Cancer Institute

\section{Source}

National Cancer Institute. Mevalonate Kinase Deficiency. NCI Thesaurus. Code C84890.

A very rare autosomal recessive disorder of cholesterol biosynthesis. It is caused by a deficiency of the enzyme mevalonate kinase, resulting in the accumulation of mevalonic acid in the urine. Signs and symptoms include psychomotor retardation, ataxia, recurrent fevers, skin rash, hepatosplenomegaly, and lymphadenopathy. 